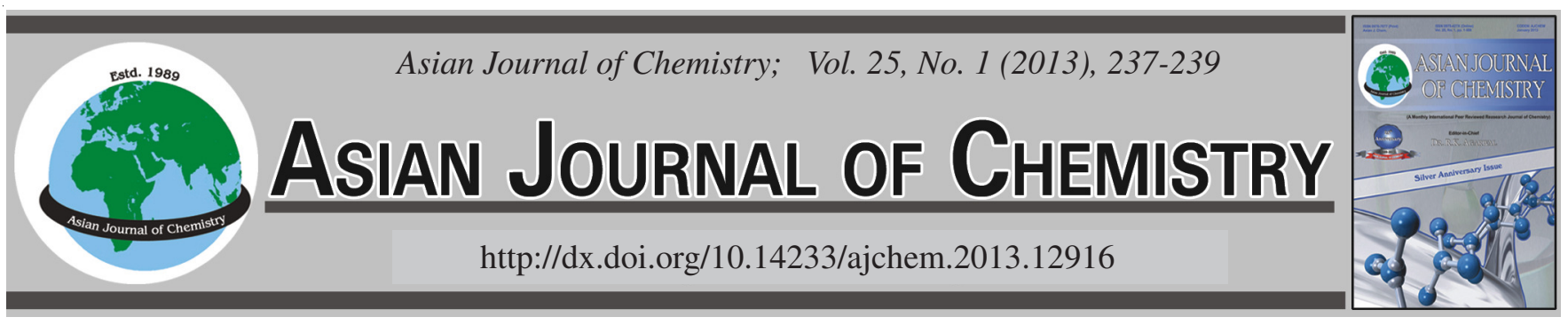

\title{
Design of a Modified Kinetic Solubility Determination Method at Laboratory Level for Early Drug Discovery
}

\author{
Gautam Singhvi ${ }^{*}$, Sachin Sonavane, Atul Gupta, Gautham Gampa and Manish Goyal
}

Department of Pharmacy, Birla Institute of Technology and Science, Pilani-333 031, India

*Corresponding author: E-mail: applab2010@gmail.com

\begin{abstract}
Thermodynamic solubility is most often determined using the equilibrium shake flask method or the pH-metric method. But these methods are time consuming and less preferable at early drug discovery. Solubility determination by dimethyl sulfoxide widely used for kinetic solubility measurement at early drug discovery. The aim of this study is to design of a DMSO based solubility determination methods and find out the extent of validity of designed method with the shake flask method. A DMSO based method is designed and solubility determined at $\mathrm{pH} 1.2$ and 6.8 at $25^{\circ} \mathrm{C}$ for model compound (hydrochlorothiazide). The solubility was also measured by shake flask method at $\mathrm{pH} 1.2$ and 6.8 at $25^{\circ} \mathrm{C}$. DMSO based solubility measured by two methods (i) titrimetric and (ii) spectrophotometric method under same conditions in both buffers. Solubility values obtained at $\mathrm{pH} 1.2$ by DMSO titrimetric method, DMSO spectrophotometric method, and shake flask methods were found to be 1047,1048 and $1109 \mu \mathrm{g} / \mathrm{mL}$ respectively. While values obtained at pH 6.8 by DMSO titrimetric method, DMSO spectrophotometric method and shake flask methods were found to be 1272,1270 and $1154 \mu \mathrm{g} / \mathrm{mL}$ respectively. The results obtained by DMSO titrimetric and spectrophotometric methods were found not to be significantly different than results obtained by standard shake flask method as compared by $t$-test at $95 \%$ confidence limit. Thus such a designed DMSO based method for solubility determination can be used at laboratory scale for preliminary solubility estimation in short time with minimum amount of drug at early drug discovery stage.
\end{abstract}

Key Words: DMSO, Kinetic solubility, Poorly soluble drugs.

\section{INTRODUCTION}

Solubility is one of the most important physico-chemical properties studied during pharmaceutical preformulation and development phase and is also required for formulation optimization and salt selection ${ }^{1}$. For solid dosage forms, solubility data are important in determining an adequate amount of drug is available for absorption in vivo ${ }^{2}$. If a compound has a low aqueous solubility, it may be subject to dissolution rate-limited or solubility-limited absorption within the gastrointestinal (GI) residence time ${ }^{3}$.

Solubility of a substance may be defined as maximum amount of that substance which can be dissolved in a particular solvent at given temperature, pressure and condition ${ }^{4}$. Depending upon property of drug we can use several methods ${ }^{5}$ to predict its solubility using equilibrium solubility methods; shake flask method ${ }^{6}$ and non-equilibrium solubility methods (DMSO solubility method, turbidity, etc). Out of these methods most reliable method is saturation solubility method. Thermodynamic solubility methods add aqueous buffer directly to compound and mix the solution for an extended time until it reaches or approaches equilibrium ${ }^{7}$. Thermodynamic solubility data are most appropriate for crystalline material that is studied in detail during late drug discovery and development. Thermodynamic solubility is most often determined using the equilibrium shake flask method ${ }^{8,9}$ or the $\mathrm{pH}$-metric method $^{10}$.

Kinetic solubility is a non-equilibrium solubility, which can be used during early drug discovery of new chemical entity and for lead optimization ${ }^{1,11}$. The usefulness and application of the solubility data from these non-equilibrium methods often is questionable for formulation development and dosage form design. The purpose of kinetic solubility measurements is to identify compounds that do not have good kinetic solubility even in aqueous buffer containing DMSO, to guide modification of structures to improve solubility, and to guide formulation selection for animal dosing ${ }^{12}$. As compounds progress to development, typically the most stable crystal form is selected and more detailed thermodynamic solubility studies are conducted in various solvents. It is important to remember that kinetic solubility data vary with the conditions of the solution. Small changes in $\mathrm{pH}$, organic solvent, ionic strength, ions in solution, co-solutes, incubation time, and temperature 
TABLE-1

SOLUBILITY BY DMSO BASED TITRATION METHOD

\begin{tabular}{lccccc}
\hline Solvent system & $\begin{array}{c}\text { Average number } \\
\text { of drops }\end{array}$ & $\begin{array}{c}\text { Volume of } \\
\text { drops }(\mathrm{mL})\end{array}$ & $\begin{array}{c}\text { Total volume for drug } \\
\text { solubilization }(\mathrm{mL})\end{array}$ & $\begin{array}{c}\text { Amount of drug } \\
\text { dissolved }\end{array}$ & $\begin{array}{c}\text { Solubility } \\
(\mu \mathrm{g} / \mathrm{mL})\end{array}$ \\
\hline DMSO & 38 & 1 & - & - & - \\
For pH 1.2 buffer $(50 \mathrm{~mL})$ & 10 & 0.26 & $50+0.26$ & 52.63 & 1047 \\
For pH 6.8 buffer $(50 \mathrm{~mL})$ & 12 & 0.32 & $50+0.32$ & 64 & 1272 \\
\hline
\end{tabular}

can result in large changes in the solubility of a compound ${ }^{13}$. Dimethyl sulfoxide is widely used in kinetic solubility determination at early drug discovery. Dimethyl sulfoxide can dissolve a wide range of drugs due to its aprotic nature. Kinetic solubility has two distinguishing characteristics: (a) the compound initially is fully dissolved in an organic solvent (e.g., DMSO) then added to the aqueous buffer and (b) equilibrium is not reached between dissolved compound and solid compound. Here using the basic concept of kinetic solubility, a new solubility determination method was designed at laboratory scale. Dimethyl sulfoxide based method can give a preliminary idea about solubility of a drug. These methods can determine the drug solubility in short time using a little amount of drug ${ }^{13}$.

Hydrochlorothiazide is used here as a model drug. It is a BCS class IV drug i.e. is low soluble and low permeable drug ${ }^{14}$. So solubility of such drug can be determined quickly by using DMSO method which will give an estimate solubility value. But the true solubility value can be determine by shake flask method.

\section{EXPERIMENTAL}

Solubility of model drug was determined with DMSO method and shake flask method. In DMSO method drug has to predissolve in DMSO and solubility determined by titration method and spectrophotometric method.

\section{Dimethyl sulfoxide based methods}

Titration method: Number of drops in $1 \mathrm{~mL}$ of pipette was counted three times with DMSO. Volume of each drop was calculated. $200 \mathrm{mg}$ of drug was added to $1 \mathrm{~mL}$ of DMSO. Drug solution in DMSO was added to $50 \mathrm{~mL}$ of buffer solutions. The number of drops required for just opalescence was noted three times in each buffer. Opalescence in buffer shows the excess drug, which came out as precipitation. Drug amount was calculated with the number of drops miscible in buffer system ${ }^{15}$.

Spectrophotometric method: Stock solution of drug in both buffer systems was prepared of concentration 5, 10, 20, 25 , and $30 \mu \mathrm{g} / \mathrm{mL}$ in triplicate. The absorbances of above prepared concentrations were taken on UV spectrophotometer at $\lambda_{\max } 272 \mathrm{~nm}$ and calibration curve was plotted. As process mentioned in titration method, DMSO drug solution added in excess to get precipitate. Precipitate was filtered. Filtrate was diluted suitably with buffer and absorbance was measured. This process repeated three times for each buffer. This absorbance further converted to concentration with calibration curve equation of drug in that buffer.

Shake flask method: Conical flask were filled with the buffered solutions $(50 \mathrm{~mL})$ of $\mathrm{pH} 1.2$ and 6.8. To each solution, excess of drug was added. All the solutions were kept for shaking in Orbital Shaker, the temperature was set to $25^{\circ} \mathrm{C}$.
From this flask a $100 \mu \mathrm{L}$ clear supernatant was taken and the volume was made up with respective buffers. The above samples were analyzed by previously developed UV spectrophotometric method.

\section{RESULTS AND DISCUSSION}

\section{Dimethyl sulfoxide based methods}

Titration method: One $\mathrm{mL}$ pipette was standardized by counting the number of drops in $1 \mathrm{~mL}$ volume of DMSO. There were 38 drops found in $1 \mathrm{~mL}$ DMSO. $200 \mathrm{mg}$ of drug was dissolved in $1 \mathrm{~mL}$ of DMSO. This DMSO drug solution added drop by drop to $50 \mathrm{~mL}$ buffer solution till just opalescence appeared. Total drug dissolved in buffer $\mathrm{pH} 1.2$ and 6.8 was found to be $1.047 \mathrm{mg} / \mathrm{mL}$ and $1.272 \mathrm{mg} / \mathrm{mL}$ respectively (Table -1 ).

Spectrophotometric method: Stock solutions of drug in both buffer systems were prepared of concentration 5, 10, 20, 25 and $30 \mu \mathrm{g}$ per $\mathrm{mL}$ in triplicate. The absorbances of above prepared concentrations were taken on UV spectrophotometer at $\lambda_{\max } 272 \mathrm{~nm}$. DMSO drug solution was added to buffer solution drop wise drop till a precipitate found. Precipitate was filtered. A $100 \mu \mathrm{L}$ Filtrate was diluted with buffer and absorbance was observed at by UV spectrophotometer (Jasco $570)$ in triplicate. The solubility was found to be $1.048 \mathrm{mg} /$ $\mathrm{mL}$ and $1.270 \mathrm{mg} / \mathrm{mL}$ buffer $\mathrm{pH} 1.2$ and 6.8 respectively (Table- 2).

\begin{tabular}{ccc}
\multicolumn{3}{c}{ TABLE-2 } \\
\multicolumn{3}{c}{$\begin{array}{c}\text { SOLUBLITY BY DMSO BASED SPECTRO- } \\
\text { PHOTOMETRIC METHOD }\end{array}$} \\
\hline Sample & Absorbance $(\mathrm{pH} 1.2)$ & Absorbance $(\mathrm{pH} \mathrm{6.8)}$ \\
\hline 1 & 0.4033 & 0.4250 \\
2 & 0.4035 & 0.4351 \\
3 & 0.4037 & 0.4202 \\
Average & 0.4033 & 0.4267 \\
Solubility & $1048 \mu \mathrm{g} / \mathrm{mL}$ & $1270 \mu \mathrm{g} / \mathrm{mL}$ \\
\hline
\end{tabular}

Shake flask method: Excess of drug added to a $250 \mathrm{~mL}$ conical flask with $50 \mathrm{~mL}$ of buffer. Both buffer solutions were kept for shaking in orbital shaker for $48 \mathrm{~h}$. A $100 \mu \mathrm{L}$ clear supernatant was taken and diluted to $20 \mathrm{~mL}$ and samples were analysed by UV spectrophotometer. The solubility was found to be $1109 \mu \mathrm{g} / \mathrm{mL}$ and $1154 \mu \mathrm{g} / \mathrm{mL}$ in buffer $\mathrm{pH} 1.2$ and 6.8 respectively.

Comparative solubility: Solubility determined with DMSO based methods compared with shake flask method. It was found that drug solubility has no significant difference between two methods (Table-3). But it is not suggested to determine drug solubility by DMSO during pharmaceutical preformulation of a drug for product development. DMSO based method can be used for drug discovery and structure modification at early stage decision for lead optimization with solubility. 


\begin{tabular}{lcc}
\hline \multicolumn{3}{c}{ TABLE-3 } \\
COMPARATIVE SOLUBILITY \\
\hline \multicolumn{1}{c}{ Method } & $\begin{array}{c}\text { Drug solubility } \\
\text { in pH 1.2 } \\
(\mu \mathrm{g} / \mathrm{mL})\end{array}$ & $\begin{array}{c}\text { Drug solubility } \\
\text { in pH 6.8 } \\
(\mu \mathrm{g} / \mathrm{mL})\end{array}$ \\
\hline (A) DMSO based methods & & \\
(i) Titration method & 1047 & 1272 \\
(ii) Spectrophotometric method & 1048 & 1270 \\
(B) Shake flask method & 1109 & 1154 \\
\hline
\end{tabular}

\section{Conclusion}

Determination of solubility using DMSO is quicker and yield approximately same result as given by saturation solubility study. The results obtained by DMSO titrimetric and spectrophotometric methods were found not to be significantly different than results obtained by standard shake flask method as compared by t-test at $95 \%$ confidence limit. Thus such a designed DMSO based method for solubility determination can be used at laboratory scale for poorly soluble drugs very easily in short time using minimum quantity of drugs in the early drug discovery. But such non-equilibrium methods are not always reliable for Preformulation study for formulation development. The usefulness of the solubility data from these non-equilibrium methods often is questionable. Some pharmaceutical companies use these data as a first criterion to eliminate poorly soluble compounds. Thus such methods of solubility determination can be used where preliminary solubility study is required in short time and drug amount is not available in plenty.

\section{REFERENCES}

1. C. Lipinski, F. Lombardo, B.W. Dominy and P.J. Feeney, Adv. Drug Deliv. Rev., 23, 3 (1997).

2. X.Q. Chen and S. Venkatesh, Pharm. Res., 21, 1758 (2004).

3. R. Lobenberg, G.L. Amidon and M. Vieira, Solubility as a Limiting Factor to Drug Absorption. Oral Drug Absorption, Prediction and Assessment, Marcel Dekker, Inc., New York, NY, pp. 137-153 (2000).

4. S.H. Yalkowsky and S.C. Valvani, J. Pharm. Sci., 69, 912 (1980).

5. S.H. Yalkowsky and S. Banerjee, Aqueous Solubility, Methods of Estimation for Organic Compounds. Marcel Dekker, New York, NY (1992).

6. A. Glomme, J. Marz and J.B. Dressman, J. Pharm. Sci., 94, 1 (2004).

7. K.J. Box, G. Völgyi, E. Baka, M. Stuart, K. Takács-Novák and J.E.A. Comer, J. Pharm. Sci., 95, 1298 (2006).

8. T. Higuchi and K.A. Connors, Adv. Anal. Chem. Inst., 4, 117 (1965).

9. C. Lipinski, in eds.: H. Van de Waterbeemd, H. Lennernas and P. Artursson, Estimation of Solubility, Permeability, Absorption and Bioavailability. Drug Bioavailability. Wiley-VCH Verlag GmbH, Weinheim, pp. 215-231 (2003).

10. A. Avdeef, Pharm. Pharmacol. Commun., 4, 165 (1998).

11. C.D. Bevan, and R.S. Lloyd, Anal. Chem., 72, 1781 (2000).

12. A. Avdeef, High-throughput Measurements of Solubility Profiles. Pharmacokinetic Optimization in Drug Research: Biological, Physicochemical and Computational Strategies, [LogP2000, Lipophilicity Symposium], 2nd, Lausanne, Switzerland, Mar. 5-9, (2000), pp. 305-325 (2001).

13. E.H. Kerns and L. Di, Drug-Like Properties: Concepts, Structure Design and Methods: from ADME to Toxicity Optimization, Academic Press (2008).

14. E. Baka, J.E.A. Comer and K. Takács-Novák, J. Pharm. Biomed. Anal., 46, 335 (2008).

15. L. Pan, Q. Ho, K. Tsutsui and L. Takahashi, J. Pharm. Sci., 90, 521 (2001). 